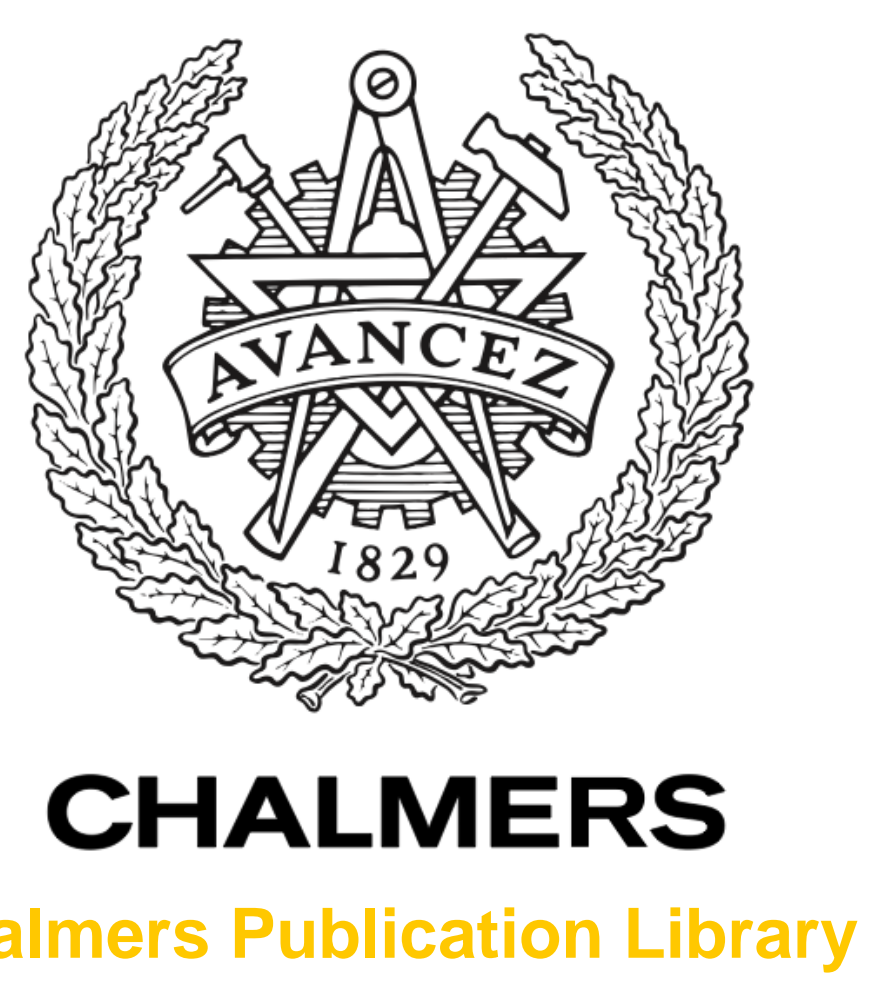

Chalmers Publication Library

Social Implications of Introducing Innovative Technology into a Product-Service
System: The Case of a Waste-Grading Machine in Electronic Waste Management

This document has been downloaded from Chalmers Publication Library (CPL). It is the author's version of a work that was accepted for publication in:

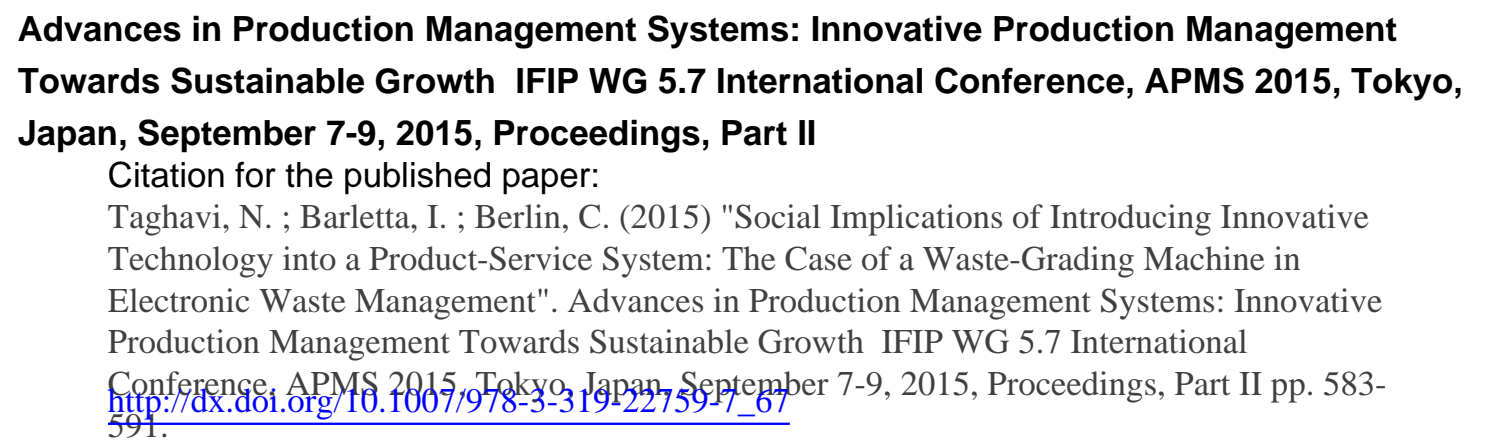

Downloaded from: http://publications.lib.chalmers.se/publication/223277

Notice: Changes introduced as a result of publishing processes such as copy-editing and formatting may not be reflected in this document. For a definitive version of this work, please refer to the published source. Please note that access to the published version might require a subscription.

Chalmers Publication Library (CPL) offers the possibility of retrieving research publications produced at Chalmers University of Technology. It covers all types of publications: articles, dissertations, licentiate theses, masters theses, conference papers, reports etc. Since 2006 it is the official tool for Chalmers official publication statistics. To ensure that Chalmers research results are disseminated as widely as possible, an Open Access Policy has been adopted.

The CPL service is administrated and maintained by Chalmers Library. 


\title{
Social Implications of Introducing Innovative Technology into a Product-Service System: the Case of a Waste- Grading Machine in Electronic Waste Management
}

\author{
Naghmeh Taghavi ${ }^{1}$, Ilaria Barletta ${ }^{2}$, Cecilia Berlin ${ }^{2}$ \\ ${ }^{1}$ Department of Technology Management and Economics, Division of Operations \\ Management, Chalmers University of Technology, Göteborg, Sweden \\ 2 Department of Product and Production Development, Division of Production \\ Systems, Chalmers University of Technology, Göteborg, Sweden \\ cecilia.berlin@chalmers.se
}

\begin{abstract}
This paper examines the social implications of introducing a new technology into the product-service system (PSS) of electronic waste management (EWM). Using a previously established set of social sustainability key performance indicators (KPIs) targeting the operations level (i.e. impacts on EWM operators), social implications are examined in a case where a specific innovative new technology is introduced to replace manual sorting of e-waste into re-use, refurbish and recycle fractions. The social sustainability KPIs were applied to the case as a structured interview guide. The results showed that the KPI framework provided a good basis for examining the social impacts and also stimulated discussions about potential business impacts based on the human resources in the system. The framework showed that the implementation supported proactive social sustainability, but some additional conditions need to be addressed by the customer organization to make sure that potential risks (identified in the interview) are mitigated.
\end{abstract}

Keywords: Social sustainability, Key Performance Indicators, Product-Service systems, Electronic Waste Management, Social Impacts

\section{Introduction}

The last few decades have seen an increased focus on the concept of sustainable development [1] in operations [2] due to global restrictions, legislations and customers' awareness of sustainability together with a global competitive environment. Considerable progress has been made with the environmental aspect, e.g. by implementing new "greener" technologies. Among the three sustainability "pillars", i.e. environmental, economic and social, the aspect of social sustainability has been widely acknowledged as the least developed [3-5], especially in the operations context. The literature provides a very broad scope for the social aspect ranging from a global to a local scale, sometimes without distinguishing that achieving social sustainability may require different approaches in developed and developing countries. To this end, solutions are sought both in the high-level strategic sense and the lower-level technological implementation sense. As a result, it has traditionally been difficult to define an operative scope for manufacturing companies aspiring to improve social 
sustainability on a factory level, although a distinction between "traditional" and "emergent" aspects of social sustainability has appeared in later years [6]. Some emergent social sustainability concerns in developed countries include demographic trends like aging populations with shortage of qualified labor as a result, and the increased importance of making manufacturing a more attractive future workplace option to attract new generations of workers [7]. Alongside this, many parallel developments drive incentives to further automate manufacturing processes, particularly those that are hazardous, monotonous or physically strenuous. Overall, social impacts on operators at factory level resulting from new automation technologies and business solutions, remains an important research topic.

There are several reasons for a manufacturing company to adopt product-service systems [8]. These can influence sustainable development by extending producers' "involvement and responsibility to phases in the life cycle, which are usually outside the traditional buyer-seller relationship, such as take back, recovery, reuse and refurbishment and remanufacturing." [8]. Regarding environmental and economical sustainability, an increasing industrial emphasis is being placed on the "end-of-life" (EoL) stage of consumer products. In some countries, producers of various consumer goods are tasked with the responsibility of taking care of the products once they have left the hands of customers and become waste [9]. Within the industry context, previous research efforts ([8],[10]) have addressed the environmental and economic impacts of implementing PSS, whereas other studies like [11],[12] have considered the societal impacts of it but without addressing implications for the factory operators specifically. One particularly interesting form of PSS is Electronic Waste Management (EWM), a burgeoning industry that turns electronic waste from an environmental threat into a resource for society. According to [13], “today e-waste sorting is performed mostly by humans, as up to now they are the most flexible and self-learning resource available. Operators not properly equipped by protective devices get exposed to hazardous substances from electronics' segregation”. However, technological solutions for waste sorting and grading are on the rise. Apart from the advantage that automating e-waste sorting can reduce human operators' unnecessary exposure to hazardous substances leaking out of e-waste materials, it remains to be examined what social impacts such a development can have on human operators at factory level.

Therefore, this study aims to explore the implications of social sustainability key performance indicators in a specific case of introducing a new technology (in the form of waste sorting equipment) into an EWM PSS. This is examined by using a framework of previously established social sustainability key performance indicators (KPIs) as a starting point [14].

\section{Theoretical framework}

\subsection{Product-service systems (PSS)}

PSS is a term that has been defined as "a marketable set of products and services capable of jointly fulfilling a user's need. The product/service ratio in this set can vary, either in terms of function fulfilment or economic value" [15]. Various authors have proposed different classifications of PSS [15-17], of which the three most distinct classification categories are product-related services, use-oriented services and result-oriented services. According to Mont (2002), from a company perspective adopting a PSS can 
add to products' value, base growth strategy on innovation, improve the company/ consumer relationship, improve the total value for the customer by extending products' life-cycle, extending products' function through upgrading and refurbishment and also making the product useful after its life cycle ends through recycling or reuse, and also helps the company implement take-back legislations.

\subsection{Socially sustainable work systems}

There is no wholly agreed-upon definition in literature of what constitutes a socially sustainable work system, but [18] defines it as a system that has achieved a high level in three main aspects: quality of work, quality of the organization and the quality of connections with the environment. To achieve a socially sustainable manufacturing work system that can combat the aforementioned demographic challenge, it should be able to meet the needs of both current and future employees. To that end, it should be able to attract different societal groups as potential workers, i.e. younger, elderly, women, disabled and in general support greater diversity. In [14],[19] the authors have used the key aspects of socially successful work systems from literature to develop a framework of social sustainability related KPIs, presented in Table 1.

Table 1. Key performance indicators of socially sustainable operations (adapted from [12] \& [17])

\begin{tabular}{|l|l|}
\hline Key performance indicators & References \\
\hline $\begin{array}{c}\text { Labour code of conduct: } \\
\bullet \quad \text { Occupational health and safety }\end{array}$ & {$[20],[21]$} \\
$\bullet \quad$ No of incidents/ high risks related to occupation & \\
\hline Personal development, Talent management and career development & {$[7],[18],[20],[22-26]$} \\
\hline $\begin{array}{l}\text { Work design } \\
\bullet \quad \text { Challenging \& stimulating job }\end{array}$ & {$[7],[18],[22-$} \\
$\bullet \quad$ Empowerment & $24],[27],[28]$ \\
\hline Work-life balance & \\
\hline Employee Turnover and Satisfaction management & {$[23],[29-33]$} \\
\hline Job Security & {$[23],[34-36]$} \\
\hline
\end{tabular}

\section{$3 \quad$ Method and case description}

\subsection{Method}

The overall research approach for this paper has been to perform a qualitative case study, incorporating a literature study, observations and interviews as we strived to explain a complex phenomenon under investigation [37]. General data regarding the EWM case were collected mainly through semi- and unstructured interviews and study visits to the EWM facility. After the initial studies the aforementioned framework of 
social sustainability KPIs from [14] was employed as a structured interview with a company representative who elaborated specific impacts on human stakeholders.

\subsection{Case description}

EWM systems challenge the ideas of traditional business models, both by adding value to something previously considered worthless, and in this particular case, by the fact that their system components (equipment and personnel) are accessible partially as a product and as a service. This case studies the REFIND company, which has developed and introduced a new automation technology called the E-grader to sort, grade and recycle e-waste using optical sorting [38]. The E-grader is available both as an equipment for rent and as a service where customers (e.g. retailers of electronic consumer goods) send spent e-waste to REFINDs facility for sorting and grading into useable "fractions". In other words, the E-grader itself is a PSS being implemented into another PSS (the EWM system) in a "nested" fashion. According to [13] the E-grader is able to distinguish much more rapidly than human workers which products are suitable to reuse, refurbish or recycle. During waste sorting, data regarding the products' type, brand, model, year to market etc. are recorded automatically. Other data fields can be added based on the companies' specific needs. By contrast, today's manual e-waste sorting cannot store workers' knowledge and WEEE items' data into a structured data management system.

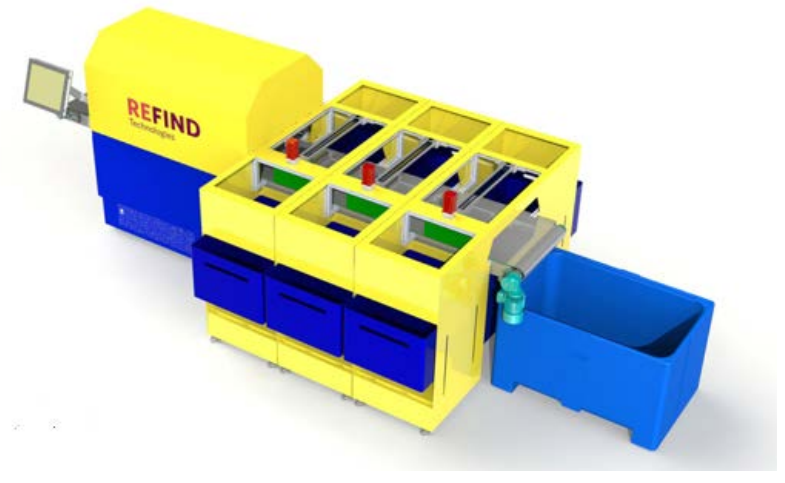

Fig. 1. The E-grader, an automatic equipment solution for e-waste sorting and grading developed by [38].

The environmental and economic aspects of the E-grader were the main drivers for its introduction as a solution for EWM systems. Some major motivations for automating the extraction of re-purposable fractions from e-waste are described in greater detail in [39] and include: the presence of valuable and rare earth materials in the e-waste products (e.g. copper, iron, steel, gold, silver and platinum); minimizing human and environmental exposure to hazardous substances that can damage health; and increased manufacturer responsibility for addressing the end-of-life (EOL) phase of their products. 


\section{$4 \quad$ Findings and analysis}

This section presents and qualitatively analyses interview data from the case company. Each topic heading reflects its corresponding indicator from Table 1, and words in cursive signal the relationship of findings to specific KPIs.

\subsection{Labour code of conduct}

For the sake of their health and safety, operators need to be carefully protected from exposure to dirt and toxic substances, which are typical for the manual electronics' segregation process of e-waste handling. Introducing the E-grader to the system will reduce the exposure of operators to acid-resistant substances. However, the operators need to be prepared and trained in terms of safety procedures and health issues regarding the new equipment, e.g. safety implications from loading, unloading, turning it on, etc. These tasks are not considered to be high-risk operations in general, but if the operators are not well-trained, incidents and accidents may occur. The effect on absenteeism numbers is two-fold. The rate of absenteeism related to health and safety issues will depend on the training level of operators as discussed above; numbers might even increase if training is not sufficient and accidents occur. However, since the new technology will affect the employees' satisfaction level and happiness and work-life balance, it could also reduce absenteeism. Due to the new technology's positive impacts on process efficiency, the company margin is expected to increase. Moreover the operators will perform higher-skilled tasks. Therefore, the operators' salary and the monetary incentives can be affected in positive way.

\subsection{Personal development, talent management and career development}

As described in 3.2, adding the E-grader to the EWM process results in knowledge and intelligence being added to the sorting process. This can unlock more opportunities for personal development of the people working with the system, because the system stores and aggregates statistics on the sorted fractions. Once the data and different dimensions of it become accessible, the operators can explore the dataset, understand the statistics, make forecasts and "control" their cash flows. When operators "use their brain" as opposed to simply handling waste, managers have an opportunity for talent management by recognizing good ideas from workers and incentivizing them.

\subsection{Work design}

Currently the manual tasks performed by operators are monotonous tasks. Introducing the E-grader to the system opens up for more diverse tasks and therefore more possibilities of job rotations. Moreover, people that work with the data management part are called to understand these data and map them properly. Therefore the job becomes more stimulating for them compared to pure materials handling. At the same time, the operators may experience more participation and empowerment as they are expected to independently come up with ideas, reports, findings and conclusions based on used electronics statistics. As the system adapts to new specifics within regulations and recycling schemes or market changes, operators will also learn new skills and will be personally developed, which can lead to more satisfied employees. 


\subsection{Work-Life balance}

The implementation of the E-grader can affect work-life balance due to the shift in the operators' responsibilities, but will also make some of the tasks location-independent and self-organised, particularly the tasks which pertain to analysing the data. This means that operators could take care of some non-loading-related tasks remotely, decreasing the need to spend time at the sorting facility, which will affect the work-life balance.

\subsection{Employee turnover and satisfaction management}

Right now manual e-waste handling suffers from very huge turnovers, not only due to the menial work in itself but also due to the very low salaries. Introducing the E-grader and new tasks is expected to reduce the turnover because of higher job satisfaction and higher salaries caused by more profit.

\subsection{Job security}

Implementing a technology that can replace several operators might affect the number of jobs in a negative way. On the other hand, as operators become more knowledgeable they will become more important assets for the company. Also, since the new technology can make the company more profitable, these two impacts can secure the operators' jobs in a positive and more sustainable way.

\section{$5 \quad$ Discussion \& Conclusion}

Methodical approaches to examining social impacts of PSS remain scarce, but this case study indicates some promising first steps towards their development. The Social sustainability KPIs suggested by [14] made an efficient inquiry possible into social impacts of introducing a technological innovation to an EWM PSS. In this particular case, the framework clearly highlighted the advantages and disadvantages for operators of implementing the technology. This case also suggests that this PSS may have potential to support proactive aspects of social sustainability, something that is argued as very important in [14]. Based on the interview results, the authors note that some additional conditions, that the technology itself cannot not provide, need to be secured by the organization implementing the E-grader, in order to ensure a socially sustainable implementation:

- Education and training must be provided to employees using the equipment to prevent injuries and to make sure that the aggregated data is exploited well

- Workers must be made aware that new responsibilities are expected of them, such as analyzing the data and coming up with new ideas, in order to gain the advantage of more varied and meaningful work, increased participation and empowerment

- Tradeoffs between number of job opportunities and meaningful work content must be managed by companies.

In conclusion, the previously established list of Social Sustainability KPIs provided a helpful framework for inquiring about social implications in the implementation of a technological innovation in an EWM PSS, as demonstrated in this case. 
Acknowledgements. The authors warmly thank Hans Eric Melin, interviewed over the proceeding of this study. This work is funded by VINNOVA (Swedish Agency for Innovation Systems) through the WEEE ID project. This work has been carried out within the Sustainable Production Initiative and the Production Area of Advance at Chalmers. The support is gratefully acknowledged.

\section{References}

1. Brundtland, G.H., Report of the World Commission on environment and development:" our common future.". United Nations (1987)

2. Elkington, J., Cannibals with forks: the triple bottom line of twenty first century business. Capstone, Mankato, MN (1997)

3. Vallance, S., H.C. Perkins, and J.E. Dixon, What is social sustainability? A clarification of concepts. Geoforum. 42(3): pp. 342-348 (2011)

4. Collins, E., J. Roper, and S. Lawrence, Sustainability practices: trends in New Zealand businesses. Business Strategy and the Environment. 19(8): pp. 479-494 (2010)

5. Omann, I. and J.H. Spangenberg. Assessing social sustainability. in BIENNIAL CONFERENCE OF THE INTERNATIONAL SOCIETY FOR ECOLOGICAL ECONOMICS.(2002).

6. Colantonio, A., Social sustainability: exploring the linkages between research, policy and practice. Springer (2011)

7. Berlin, C., et al., Social sustainability challenges for european manufacturing industry: Attract, recruit and sustain, in Advances in Production Management Systems. Sustainable Production and Service Supply Chains. Springer. pp. 78-85(2013)

8. Mont, O.K., Clarifying the concept of product-service system. Journal of cleaner production. 10(3): pp. 237-245 (2002)

9. Directive 2012/19/EU of the European Parliament and of the Council of 4 July 2012 on waste electrical and electronic equipment, WEEE. Official Journal of the European Union L. 197: pp. 38-71 (2012)

10. Aurich, J.C., C. Fuchs, and C. Wagenknecht, Life cycle oriented design of technical ProductService Systems. Journal of Cleaner Production. 14(17): pp. 1480-1494 (2006)

11. Peruzzini, M., M. Germani, and E. Marilungo. Design for Sustainability of Product-Service Systems in the Extended Enterprise. in ISPE CE.(2013).

12. Armstrong, C.M., et al., Sustainable product-service systems for clothing: exploring consumer perceptions of consumption alternatives in Finland. Journal of Cleaner Production. (2014).

13. Barletta, I., et al., Fostering sustainable electronic waste management through intelligent sorting equipment: Submitted to the IEEE CASE 2015 Special Session (2015)

14. Taghavi, N., C. Adams, and C. Berlin. Social Sustainability KPIs in Operations Management: A Gap between the Reactive and the Proactive Stance. in Swedish Production Symposium 2014, SPS14 (2014)

15. Goedkoop, M.J., Product service systems, ecological and economic basics. Ministry of Housing, Spatial Planning and the Environment, Communications Directorate (1999)

16.Zaring, O., et al., Creating eco-efficient producer services. Gothenburg, Gothenburg Research Institute. 503 (2001)

17. Tukker, A., Eight types of product-service system: eight ways to sustainability? Experiences from SusProNet. Business strategy and the environment. 13(4): pp. 246-260 (2004)

18. Eijnatten, F.v. From intensive to sustainable work systems: The quest for a new paradigm of work. in Keynote Speech at the TUTB/SALTSA Conference "Working Without Limits: ReOrganising Work and Reconsidering Workers’ Health”. Brussels (2000) 
19. Adams, C., et al. Mapping the Current Social Sustainability Practices of the European Manufacturing Industry. in Swedish Production Symposium 2014, SPS14 (2014)

20. Initiative, G.R., G4 Sustainability Reporting Guidelines. Reporting Principles and Standard Disclosures, Global Reporting Initiative. Retrieved from https://www. globalreporting. org/resourcelibrary/GRIG4-Part1-Reporting-Principles-and-Standard-Disclosures. pdf (2013)

21.Joung, C.B., et al., Categorization of indicators for sustainable manufacturing. Ecological Indicators. 24: pp. 148-157 (2013)

22. Backes-Gellner, U. and S.N. Tuor, Avoiding labor shortages by employer signaling: on the importance of good work climate and labor relations. Industrial and Labor Relations Review. pp. 271-286 (2010)

23. Boswell, W.R., et al., Individual job-choice decisions and the impact of job attributes and recruitment practices: A longitudinal field study. Human Resource Management. 42(1): pp. 23-37 (2003)

24. Lewis, M.A., Lean production and sustainable competitive advantage. International Journal of Operations \& Production Management. 20(8): pp. 959-978 (2000)

25. De Brito, M.P., V. Carbone, and C.M. Blanquart, Towards a sustainable fashion retail supply chain in Europe: organisation and performance. International Journal of Production Economics. 114(2): pp. 534-553 (2008)

26. Rothwell, W.J., Career planning and succession management: developing your organization's talent--for today and tomorrow. Greenwood Publishing Group (2005)

27. Basmer, S., et al., Open Production: Chances for Social Sustainability in Manufacturing. Procedia CIRP. 26: pp. 46-51(2015)

28. Veleva, V. and M. Ellenbecker, Indicators of sustainable production: framework and methodology. Journal of Cleaner Production. 9(6): pp. 519-549 (2001)

29. Jeffrey Hill, E., et al., Exploring the relationship of workplace flexibility, gender, and life stage to family-to-work conflict, and stress and burnout. Community, Work and Family. 11(2): pp. 165-181(2008)

30. Pfeffer, J., Building sustainable organizations: The human factor. The Academy of Management Perspectives. 24(1): pp. 34-45 (2010)

31. Kovach, K.A., What motivates employees? Workers and supervisors give different answers. Business Horizons. 30(5): pp. 58-65 (1987)

32. Bourne, M., et al., Designing, implementing and updating performance measurement systems. International Journal of Operations \& Production Management. 20(7): pp. 754-771 (2000)

33. Harrington, B. and D.T. Hall, Career management \& work-life integration: using self-assessment to navigate contemporary careers. Sage (2007)

34. Barling, J., E.K. Kelloway, and R.D. Iverson, High-quality work, job satisfaction, and occupational injuries. Journal of Applied Psychology. 88(2): pp. 276 (2003)

35. Azapagic, A., Developing a framework for sustainable development indicators for the mining and minerals industry. Journal of cleaner production. 12(6): pp. 639-662 (2004)

36. Krajnc, D. and P. Glavič, Indicators of sustainable production. Springer (2004)

37. Meredith, J., Building operations management theory through case and field research. Journal of operations management. 16(4): p. 441-454 (1998)

38. REFIND technologies. [cited 2015-04-22; Available from: http://www.refind.se/.

39. Barletta, I., et al., Prerequisites for a high-level framework to design sustainable plants in the e-waste supply chain, presented at the 22nd CIRP conference on Life Cycle Engineering: Sydney (2015) 